\title{
Nanoparticle-Encapsulated Camptothecin: Epigenetic Modulation in DNA Repair Mechanisms in Colon Cancer Cells
}

\author{
Aisha Farhana ${ }^{1, *},{ }^{+}$, Avin Ee-Hwan Koh ${ }^{2,+}{ }^{,}$Jia Bei Tong ${ }^{3}$, Abdullah Alsrhani ${ }^{1} \mathbb{D}$, Suresh Kumar Subbiah ${ }^{3,4, *}$ \\ and Pooi Ling Mok ${ }^{1,2}$
}

1 Department of Clinical Laboratory Sciences, College of Applied Medical Sciences, Jouf University, Sakaka 72388, Aljouf Province, Saudi Arabia; afalserhani@ju.edu.sa (A.A.); pooi_ling@upm.edu.my (P.L.M.)

2 Department of Biomedical Sciences, Faculty of Medicine and Health Sciences, Universiti Putra Malaysia, Seri Kembangan 43400, Selangor, Malaysia; avin.keh@gmail.com

3 Department of Medical Microbiology, Universiti Putra Malaysia, Seri Kembangan 43400, Selangor, Malaysia; hanfabin1@gmail.com

4 Centre for Materials Engineering and Regenerative Medicine, Bharath Institute of Higher Education and Research, Bharath University, Chennai 600073, Tamil Nadu, India

* Correspondence: aishafarhana512@gmail.com (A.F.); pvc_gp@bharathuniv.ac.in or sureshkudsc@gmail.com (S.K.S.)

+ These authors contributed equally to this work.

check for

updates

Citation: Farhana, A.; Koh, A.E.-H.; Tong, J.B.; Alsrhani, A.; Kumar Subbiah, S.; Mok, P.L. NanoparticleEncapsulated Camptothecin:

Epigenetic Modulation in DNA Repair Mechanisms in Colon Cancer Cells. Molecules 2021, 26, 5414. https://doi.org/10.3390/

molecules26175414

Academic Editor: Raed Abu-Reziq

Received: 30 May 2021

Accepted: 14 July 2021

Published: 6 September 2021

Publisher's Note: MDPI stays neutral with regard to jurisdictional claims in published maps and institutional affiliations.

Copyright: (C) 2021 by the authors. Licensee MDPI, Basel, Switzerland. This article is an open access article distributed under the terms and conditions of the Creative Commons Attribution (CC BY) license (https:// creativecommons.org/licenses/by/ $4.0 /)$.

\begin{abstract}
Molecular crosstalk between the cellular epigenome and genome converge as a synergistic driver of oncogenic transformations. Besides other pathways, epigenetic regulatory circuits exert their effect towards cancer progression through the induction of DNA repair deficiencies. We explored this mechanism using a camptothecin encapsulated in $\beta$-cyclodextrin-EDTA- $\mathrm{Fe}_{3} \mathrm{O}_{4}$ nanoparticles (CPT-CEF)-treated HT29 cells model. We previously demonstrated that CPT-CEF treatment of HT29 cells effectively induces apoptosis and cell cycle arrest, stalling cancer progression. A comparative transcriptome analysis of CPT-CEF-treated versus untreated HT29 cells indicated that genes controlling mismatch repair, base excision repair, and homologues recombination were downregulated in these cancer cells. Our study demonstrated that treatment with CPT-CEF alleviated this repression. We observed that CPT-CEF exerts its effect by possibly affecting the DNA repair mechanism through epigenetic modulation involving genes of HMGB1, APEX1, and POLE3. Hence, we propose that CPT-CEF could be a DNA repair modulator that harnesses the cell's epigenomic plasticity to amend DNA repair deficiencies in cancer cells.
\end{abstract}

Keywords: DNA repair; epigenetic modulation; colon cancer; nanoparticles; transcriptome analysis

\section{Introduction}

Epigenetic mechanisms are essential for the ontogenesis of mammals and the maintenance of tissue-specific gene expression [1,2]. Response to developmental and environmental signals within the tissue can alter the cell epigenetics and may lead to aberrancies in phenotype, oncogenic transformations, and cancer progression [1,3-5]. The epigenetic mechanisms are deregulated in many forms of cancer including colorectal cancer [6], bladder cancer [7], and leukemia [8].

Research progress in cancer epigenetics has shown that epigenetic mechanisms in cancer undergo extensive reprogramming, including DNA methylation, histone modification, nucleosome localization, and non-coding RNA [2,9]. Two of the most common mechanisms are DNA methylation and histone modifications. DNA methylation is a process involving the addition of methyl groups to DNA regions, which typically leads to the repression of gene transcription. The two common types present in tumors are demethylation and de novo methylation of $\mathrm{CpG}$ islands [10]. These result in expression profiles that promote tumor growth. Histone modification is a form of post-translational modification occurring on histone proteins that regulate chromatin. In cancer, the deregulation of this process 
affects the maintenance of repressive chromatin, thereby causing an aberrant promotion of gene expression [11]. Genetic changes are irreversible, while epigenetic modifications are reversible. This characteristic makes epigenetic modifications a perfect target for therapeutic intervention for cancer [12].

Camptothecin (CPT) has been demonstrated to be an effective anti-cancer drug for various cancers. Due to its low solubility in aqueous media and active lactone ring instability at physiological $\mathrm{pH}[13,14]$, encapsulation by $\mathrm{CEF}$ (cyclodextrin-EDTA- $\mathrm{FE}_{3} \mathrm{O}_{4}$ ) can effectively increase its stability and feasibility for cancer therapy [15]. Encapsulation by nanomaterials is being widely researched as an effective means of drug delivery for cancer therapy [16]. One example is the use of lipid nanocapsules that allows efficient delivery of loaded drugs to the tumor tissue [17]. Cyclodextrin was used for the encapsulation in this study as it can act as a multifunctional core for diverse conjugation of drugs and other molecules [18]. Meanwhile, the superparamagnetic iron oxide nanoparticle $\left(\mathrm{Fe}_{3} \mathrm{O}_{4}\right)$ possesses high microwave absorbance; hence, it can be used to track and kill the remnant of tumor cells [19].

In the previous study, we used camptothecin encapsulated in $\beta$-cyclodextrin-EDTA$\mathrm{Fe}_{3} \mathrm{O}_{4}$ nanoparticles (CPT-CEF) for treating human colon cancer HT29 cell lines [15]. We found that CPT-CEF could induce cell apoptosis and growth inhibition by arresting the cell cycle and activating the mitochondrial apoptotic pathways. In normal cells, excessive DNA damage that cannot be repaired by DNA repair factors typically leads to cell death as a safety mechanism to prevent cancer [20]. However, tumor cells have altered or defective DNA-repair mechanisms that prevent them from undergoing apoptosis, which can be exploited therapeutically for developing new anti-cancer drugs [21,22]. As such, we would like to further examine whether genes involved in epigenetic control for DNA-repair mechanisms were affected during treatment with CPT-CEF. DNA damage and deficiency in immediate repair is the primary underlying cause for the switch from normal to malignant cells [23]. To achieve the study objective, we carried out comparative transcriptomic studies between treated and untreated cancer cells. We then attempted to profile the transcriptomics based on well-known databases such as Gene Ontology (GO), which is a repository for annotated gene interactions, and Kyoto Encyclopedia of Genes and Genomes (KEGG), which is a resource containing known biological pathways. Our results reveal three important genes, HMGB1, APEX1, and POLE3, that function in the epigenetic control of a DNA-repair mechanism, which modulates cancer in HT29 cells, and induce apoptosis.

\section{Results and Discussion}

\subsection{Mapping of List of Differentially Expressed Genes (DEGs) to Its Gene Ontology Terms}

Camptothecin demonstrates a broad-spectrum anti-cancer activity. The molecular target for camptothecin has been firmly established to be the human DNA topoisomerase-I [24]. In vivo experiments have shown that camptothecin has an inhibitory effect on tumor growth, especially on digestive tract tumors, leukemia, and bladder cancer [25-28]. The application of camptothecin in cancer treatment is limited due to its poor water solubility. However, modification with nanotechnology makes it feasible to be used in cancer therapy [29].

In the present study, upon completion of sequencing, the data were processed to generate a list of DEGs. An ORA analysis was then performed using DEGs with the cut-off $p<0.05$ and 2 -fold changes. The ORA analysis generated results based on GO biological processes. REViGO was then used to summarize the terms (Figure 1). The top 13 enriched gene sets under GO biological processes were tabulated in Table 1. A majority of the terms involved nucleotide metabolism. In the previous study, we encapsulated camptothecin in $\beta$ cyclodextrin-EDTA- $\mathrm{Fe}_{3} \mathrm{O}_{4}$ nanoparticles (CPT-CEF) to enhance the solubility and stability, and further tested its inhibitory activity on HT29 cell growth in vitro. Our data shows CPTCEF can induce caspase-3 activity and alter mitochondrial membrane potential, leading to arrest in the cell cycle, and ultimately apoptosis [15]. In addition, CPT-CEF treatment results in an enrichment of pathways involved in nucleotide metabolism (Figure 1). 


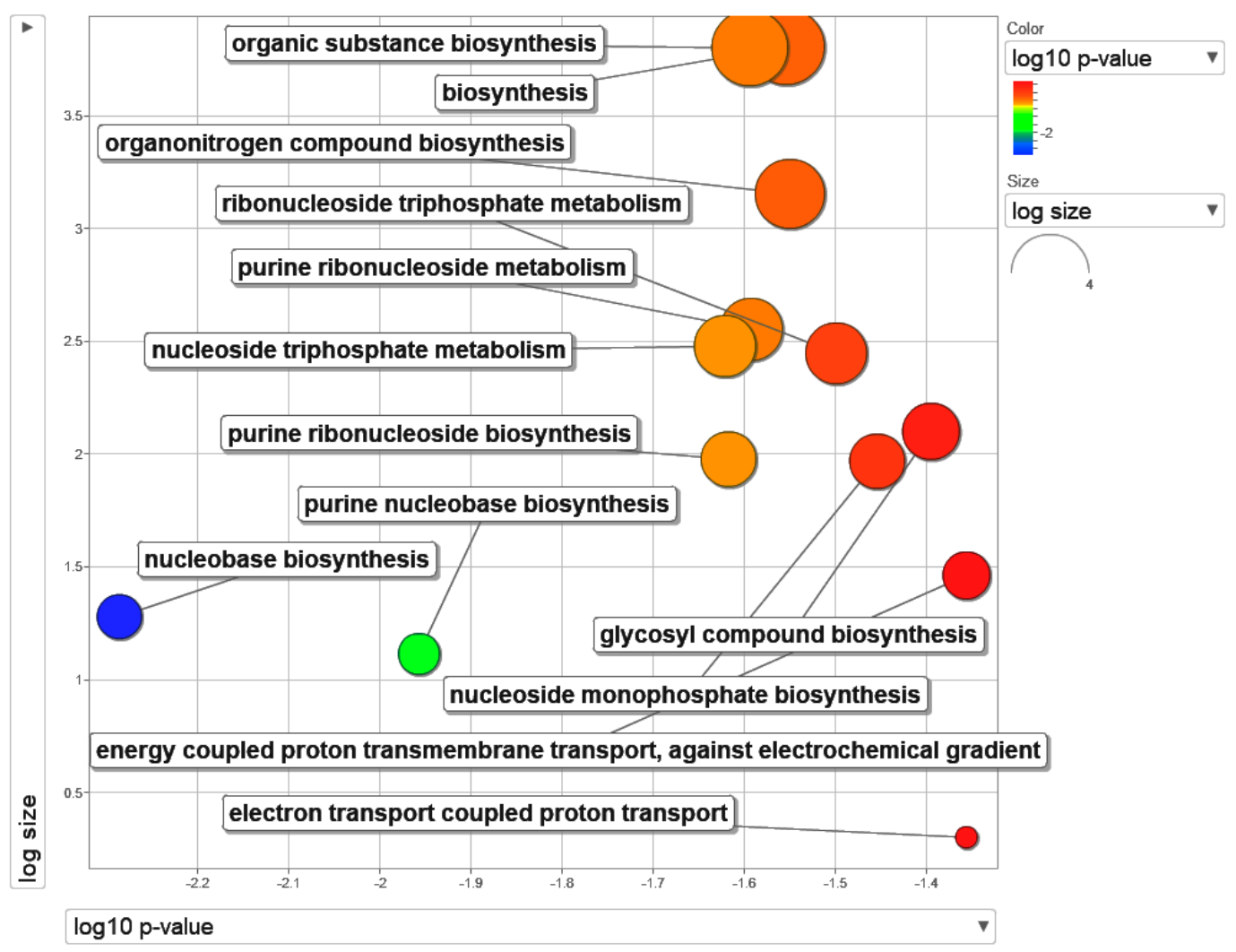

Figure 1. Visualization of the top terms in Gene Ontology (GO) biological processes obtained using over-representation analysis. The top GO terms were obtained using g:Profiler and clustered by ReVigo for visualization (adj $p<0.05)$. The data were plotted as $\log 10 p$-value against log size on a scatterplot. The GO terms were sized and colored according to the indicated scale.

Table 1. A list of the top 13 gene ontology terms for biological processes that was obtained by over-representation analysis using g:Profiler (adj $p<0.05)$.

\begin{tabular}{ccc}
\hline GO Term ID & Description & Log $\mathbf{1 0}$ Adj $\boldsymbol{p}$ \\
\hline GO:0046112 & Nucleobase biosynthetic process & -2.2861 \\
GO:0015988 & Energy-coupled proton transmembrane transport, against electrochemical gradient & -1.3562 \\
GO:0009058 & Biosynthetic process & -1.5541 \\
GO:1901576 & Organic substance biosynthetic process & -1.5941 \\
GO:1901566 & Organonitrogen compound biosynthetic process & -1.55 \\
GO:0009199 & Ribonucleoside triphosphate metabolic process & -1.499 \\
GO:0015990 & Electron transport coupled proton transport & -1.3562 \\
GO:0009124 & Nucleoside monophosphate biosynthetic process & -1.4542 \\
GO:0009141 & Nucleoside triphosphate metabolic process & -1.6213 \\
GO:0046128 & Purine ribonucleoside metabolic process & -1.5925 \\
GO:1901659 & Glycosyl compound biosynthetic process & -1.3951 \\
GO:0046129 & Purine ribonucleoside biosynthetic process & -1.6173 \\
GO:0009113 & Purine nucleobase biosynthetic process & -1.9572 \\
\hline
\end{tabular}

\subsection{Identification of Enriched KEGG Pathways in CPT-CEF-Treated HT29 Colon Cancer Cells}

In order to identify enrichment of pathways in either the treated or untreated control groups, a GSEA analysis was performed. KEGG was used as the reference database. The top 13 KEGG pathways were tabulated in Table 2. Similar to ORA analysis, a majority of the KEGG pathways involved played a role in nucleotide metabolism. There were also pathways involving DNA repair mechanisms. Our analysis showed that these pathways were enriched in the control samples. This suggests that CPT-CEF has an effect on processes involving nucleotide metabolism (Figure 2). The plots of these pathways are shown in Figure 2. The details are tabulated in Tables 1 and 2, respectively. These pathways were 
enriched in the untreated control group, suggesting that they were unperturbed in that group. The genes from the leading edge of the data are tabulated in Table 3. Hence, we further hypothesized that CPT-CEF might modulate the DNA repair mechanisms by inducing changes in the epigenome of colon cancer cells. Disruption to DNA repair responses is one of the leading causes of the development of cancer cells [23].

Table 2. A list of the top 13 KEGG pathways found enriched in CPT-CEF-treated colon cancer cells. Gene set enrichment analysis was performed using the KEGG database as a reference $(\operatorname{adj} p<0.05)$. NES, normalized enrichment score.

\begin{tabular}{ccc}
\hline WikiPathways ID & NES & $\begin{array}{c}\text { Adj } p \\
\text { Value }\end{array}$ \\
\hline KEGG_RIBOSOME & -2.61902 & 0 \\
KEGG_DNA_REPLICATION & -2.4385 & 0 \\
KEGG_PURINE_METABOLISM & -2.24033 & 0 \\
KEGG_PYRIMIDINE_METABOLISM & -2.20893 & $2.31 \times 10^{-4}$ \\
KEGG_SPLICEOSOME & -2.13383 & $5.56 \times 10^{-4}$ \\
KEGG_FRUCTOSE_AND_MANNOSE_METABOLISM & -2.10173 & 0.001798 \\
KEGG_HOMOLOGOUS_RECOMBINATION & -2.09315 & 0.001541 \\
KEGG_GLYCOLYSIS_GLUCONEOGENESIS & -2.07396 & 0.001349 \\
KEGG_MISMATCH_REPAIR & -2.04734 & 0.001544 \\
KEGG_BASE_EXCISION_REPAIR & -2.04304 & 0.001389 \\
KEGG_CYSTEINE_AND_METHIONINE_METABOLISM & -2.01921 & 0.001616 \\
KEGG_ONE_CARBON_POOL_BY_FOLATE & -1.99589 & 0.002156 \\
KEGG_PROTEASOME & -1.95564 & 0.002531 \\
KEGG_PENTOSE_PHOSPHATE_PATHWAY & -1.92024 & 0.003016 \\
\hline
\end{tabular}
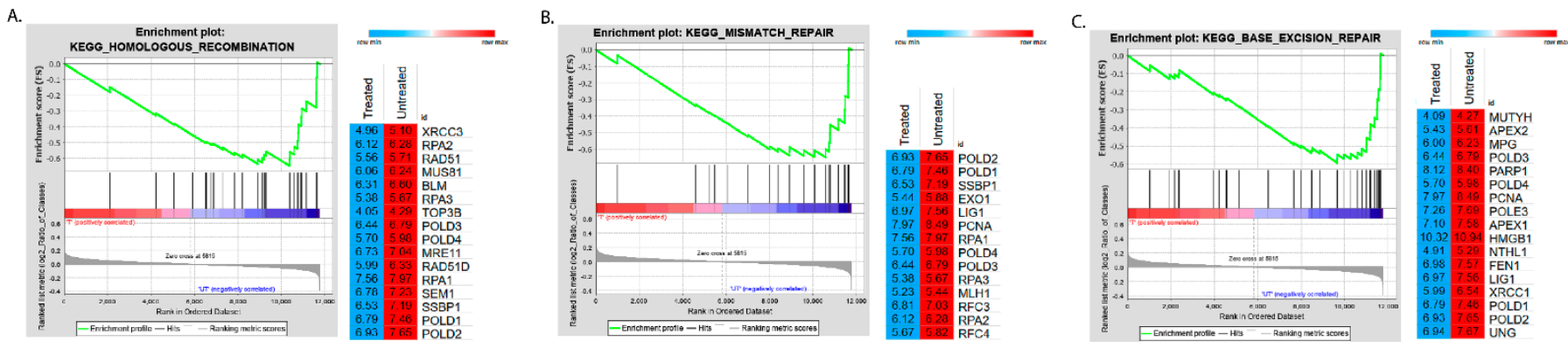

Figure 2. A gene set enrichment analysis (GSEA) of CPT-CEF-treated colon cancer cells revealed an enrichment of DNA repair mechanisms. The GSEA tool was used to make an enrichment plot of the homologous recombination (A), mismatch repair $(\mathbf{B})$, and base excision repair $(\mathbf{C})$ pathways. The genes that contributed to the leading-edge subset in the ranked list were shown in heatmaps, where the values indicated the mean normalized count data for each gene between CPF-CEFtreated and untreated samples. Red represents upregulation; blue represents downregulation.

It is worth noting that DNA repair mechanisms are also the responsible culprit for tumoral cell resistance to many cancer therapies [30]. Hence, in this study, we performed comparative transcriptomic analysis between CPT-CEF-treated and untreated HT29 cells to identify the dysregulated genes that are involved in signaling pathways associated with DNA repairs at the epigenetics level. The results of our study demonstrate that cancer cells downregulated a total of 47 genes controlling mismatch repair, base excision repair, and homologous recombination (Table 3).

\subsection{Identification of Genes Involved in Epigenetic Modulation}

Genes identified in Table 4 were then cross-referenced with the epigenetics database. It was found that HMGB1, APEX1, and POLE3 were involved with epigenetic modulation. These genes were members of the KEGG base excision repair pathway. As such, the position of these genes was visualized on the pathway (Figure 3). POLE3 can be found as a subunit of DNA polymerase epsilon (Pole) on the KEGG map. Additionally, the homologous 
recombination and mismatch repair pathways were also visualized (Figures 4 and 5, respectively). In the context of epigenetic study of cancer cell development, the analysis indicated that treatment with CPT-CEF could reverse these deficiencies by modulating the expression of these genes. To our knowledge, this is a novel study that successfully demonstrates the epigenome molecular interplay involved in DNA repair mechanisms when cancer cells are given anti-cancer drug therapy.

Table 3. A list of GSEA-enriched genes from CPT-CEF-treated colon cancer cells that are involved in the DNA repair mechanism. The genes from the leading-edge subset were ranked using GSEA and tabulated. KEGG was used as the reference map. RMS stands for ranked metric score; RES stands for running enrichment score. The genes were annotated based on Ensembl database.

\begin{tabular}{|c|c|c|c|c|}
\hline Pathway & Symbol & Description & RMS & RES \\
\hline \multirow{16}{*}{$\begin{array}{l}\text { Homologous } \\
\text { recombination }\end{array}$} & RPA2 & replication protein $\mathrm{A} 2$ & -0.03701 & -0.60918 \\
\hline & RAD51 & RAD51 recombinase & -0.04012 & -0.59841 \\
\hline & XRCC3 & X-ray repair cross complementing 3 & -0.04147 & -0.57749 \\
\hline & MUS81 & MUS81 structure-specific endonuclease subunit & -0.04274 & -0.55398 \\
\hline & BLM & BLM RecQ-like helicase & -0.06435 & -0.60186 \\
\hline & MRE11 & MRE11 homolog, double strand break repair nuclease & -0.06466 & -0.55804 \\
\hline & POLD4 & DNA polymerase delta 4 , accessory subunit & -0.0695 & -0.52524 \\
\hline & RPA3 & replication protein $\mathrm{A} 3$ & -0.0747 & -0.48659 \\
\hline & RPA1 & replication protein $\mathrm{A} 1$ & -0.07625 & -0.43647 \\
\hline & POLD3 & DNA polymerase delta 3 , accessory subunit & -0.07674 & -0.38431 \\
\hline & RAD51D & RAD51 paralog D & -0.08042 & -0.33793 \\
\hline & TOP3B & DNA topoisomerase III beta & -0.08197 & -0.28399 \\
\hline & SEM1 & SEM1 26S proteasome complex subunit & -0.0914 & -0.2371 \\
\hline & POLD1 & DNA polymerase delta 1 , catalytic subunit & -0.13575 & -0.18254 \\
\hline & SSBP1 & single-stranded DNA-binding protein 1 & -0.13701 & -0.08714 \\
\hline & POLD2 & DNA polymerase delta 2 , accessory subunit & -0.14252 & 0.009967 \\
\hline \multirow{14}{*}{ Mismatch repair } & RPA2 & replication protein $\mathrm{A} 2$ & -0.03701 & -0.6119 \\
\hline & RFC4 & replication factor $\mathrm{C}$ subunit 4 & -0.03721 & -0.58618 \\
\hline & RFC3 & replication factor $\mathrm{C}$ subunit 3 & -0.0476 & -0.60649 \\
\hline & MLH1 & mutL homolog 1 & -0.0573 & -0.60656 \\
\hline & POLD4 & DNA polymerase delta 4 , accessory subunit & -0.0695 & -0.59973 \\
\hline & RPA3 & replication protein $\mathrm{A} 3$ & -0.0747 & -0.55899 \\
\hline & RPA1 & replication protein $\mathrm{A} 1$ & -0.07625 & -0.50674 \\
\hline & POLD3 & DNA polymerase delta 3 , accessory subunit & -0.07674 & -0.45243 \\
\hline & PCNA & proliferating cell nuclear antigen & -0.09206 & -0.41689 \\
\hline & EXO1 & exonuclease 1 & -0.11252 & -0.35987 \\
\hline & LIG1 & DNA ligase 1 & -0.11726 & -0.27812 \\
\hline & POLD1 & DNA polymerase delta 1 , catalytic subunit & -0.13575 & -0.19036 \\
\hline & SSBP1 & single-stranded DNA-binding protein 1 & -0.13701 & -0.09113 \\
\hline & POLD2 & DNA polymerase delta 2 , accessory subunit & -0.14252 & 0.009963 \\
\hline \multirow{17}{*}{ Base excision repair } & APEX2 & apurinic/apyrimidinic endodeoxyribonuclease 2 & -0.04908 & -0.5695 \\
\hline & PARP1 & poly(ADP-ribose) polymerase 1 & -0.04922 & -0.54643 \\
\hline & MPG & $N$-methylpurine DNA glycosylase & -0.05495 & -0.54497 \\
\hline & MUTYH & mutY DNA glycosylase & -0.06143 & -0.54262 \\
\hline & POLD4 & DNA polymerase delta 4 , accessory subunit & -0.0695 & -0.53485 \\
\hline & POLD3 & DNA polymerase delta 3 , accessory subunit & -0.07674 & -0.51601 \\
\hline & POLE3 & DNA polymerase epsilon 3 , accessory subunit & -0.08351 & -0.49272 \\
\hline & HMGB1 & high mobility group box 1 & -0.08388 & -0.45306 \\
\hline & PCNA & proliferating cell nuclear antigen & -0.09206 & -0.42234 \\
\hline & APEX1 & apurinic/apyrimidinic endodeoxyribonuclease 1 & -0.09397 & -0.37987 \\
\hline & NTHL1 & nth-like DNA glycosylase 1 & -0.10643 & -0.34445 \\
\hline & LIG1 & DNA ligase 1 & -0.11726 & -0.29743 \\
\hline & FEN1 & flap structure-specific endonuclease 1 & -0.11774 & -0.24157 \\
\hline & $\mathrm{XRCC1}$ & X-ray repair cross complementing 1 & -0.12694 & -0.18614 \\
\hline & POLD1 & DNA polymerase delta 1 , catalytic subunit & -0.13575 & -0.12503 \\
\hline & POLD2 & DNA polymerase delta 2 , accessory subunit & -0.14252 & -0.05904 \\
\hline & UNG & uracil DNA glycosylase & -0.14332 & 0.00946 \\
\hline
\end{tabular}




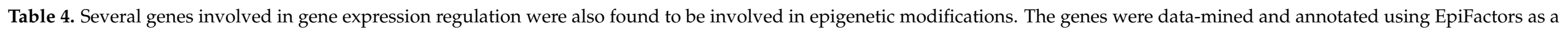
reference database. FC, fold change. NA indicates data not available.

\begin{tabular}{|c|c|c|c|c|c|c|c|c|}
\hline Symbol & Description & Function & Target Molecule & Target Entity & Product & Comment & $\operatorname{Adj} p$ & $\log _{2} \mathrm{FC}$ \\
\hline PKM & $\begin{array}{c}\text { pyruvate kinase, } \\
\text { muscle }\end{array}$ & $\begin{array}{l}\text { Histone } \\
\text { modification write } \\
\text { cofactor }\end{array}$ & histone & $\begin{array}{c}\text { H3S10, H3S28, } \\
\text { H2BS32 }\end{array}$ & $\begin{array}{l}\text { H3S10ph, } \\
\text { H3S28ph, } \\
\text { H2BS32ph, } \\
\text { H3T11ph }\end{array}$ & $\begin{array}{l}\text { Transcriptional activation by } \\
\text { epidermal growth factor (EGF) is } \\
\text { mediated via phosphorylation of } \\
\text { H3S10 H3S28 and H2BS32 by } \\
\text { Rsk-2 and PKM2. }\end{array}$ & $1.02 \times 10^{-7}$ & -1.02522 \\
\hline HMGB1 & $\begin{array}{l}\text { high mobility group } \\
\text { box } 1\end{array}$ & $\begin{array}{l}\text { Chromatin } \\
\text { remodeling }\end{array}$ & chromatin & NA & NA & $\begin{array}{l}\text { Chromatin-specific remodeling } \\
\text { by HMGB1 and linker histone H1 } \\
\text { silences proinflammatory genes } \\
\text { during endotoxin tolerance. }\end{array}$ & 0.01295 & -0.64422 \\
\hline APEX1 & $\begin{array}{l}\text { APEX nuclease } \\
\text { (multifunctional } \\
\text { DNA repair } \\
\text { enzyme) } 1\end{array}$ & $\begin{array}{l}\text { DNA modification } \\
\text { cofactor }\end{array}$ & DNA & NA & NA & $\begin{array}{l}\text { UniProt: May play a role in the } \\
\text { epigenetic regulation of gene } \\
\text { expression by participating in } \\
\text { DNA demethylation. }\end{array}$ & 0.075289 & -0.63047 \\
\hline POLE3 & $\begin{array}{l}\text { polymerase (DNA } \\
\text { directed), epsilon 3, } \\
\text { accessory subunit }\end{array}$ & Histone chaperone & histone & NA & NA & $\begin{array}{l}\text { The human homologues of two } \\
\text { novel putative histone-fold } \\
\text { proteins in Drosophila CHRAC } \\
\text { are present in HuCHRAC. } \\
\text { The two human histone-fold } \\
\text { proteins form a stable complex } \\
\text { that binds naked DNA but not } \\
\text { nucleosomes. }\end{array}$ & 0.109001 & -0.54009 \\
\hline
\end{tabular}


BASE EXCISION REPA R

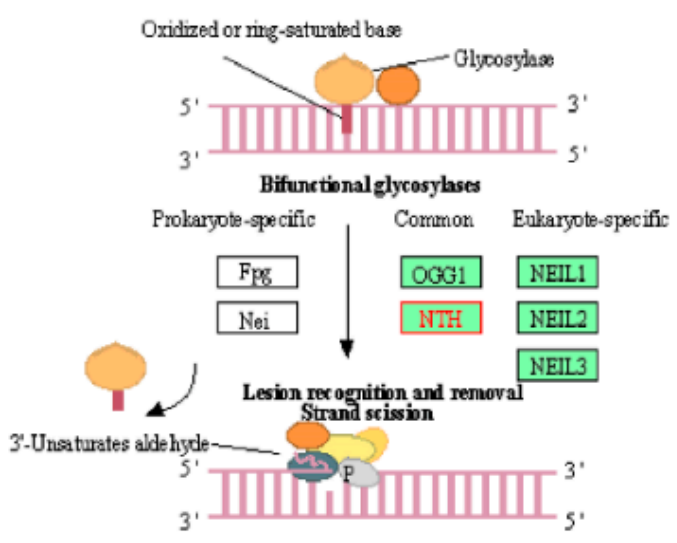

AP-endonuclease

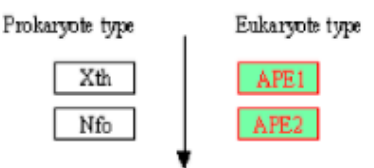

3'-Terminal unsaturated sugar removal

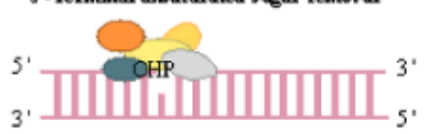

Prokaryote type

Dpol

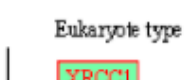

XRCC1

PolB

$\checkmark$

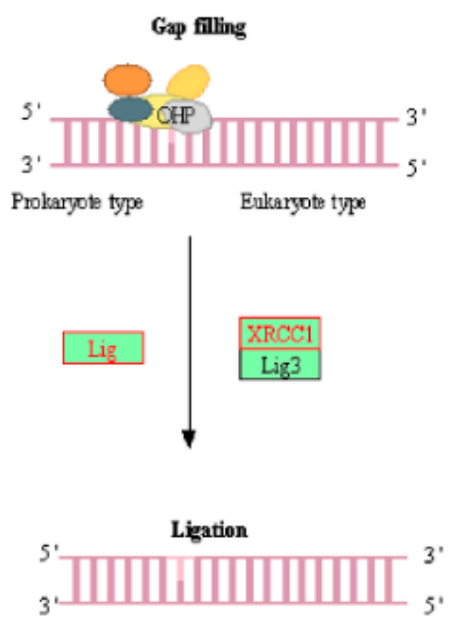

Short patch BER

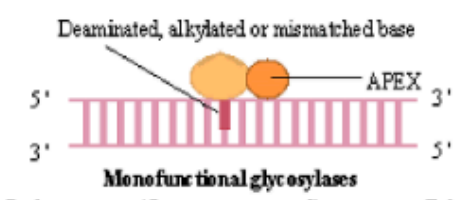

Prokaryole-grecific

Common Eukaryote-specific

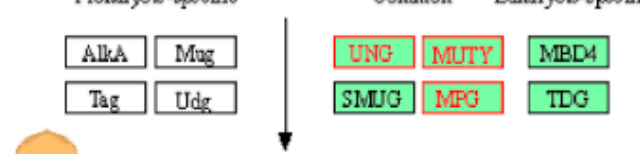

14 Lesion recognition and removal

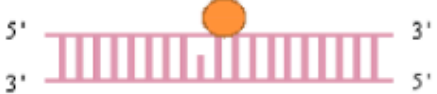

AP-endomuclease
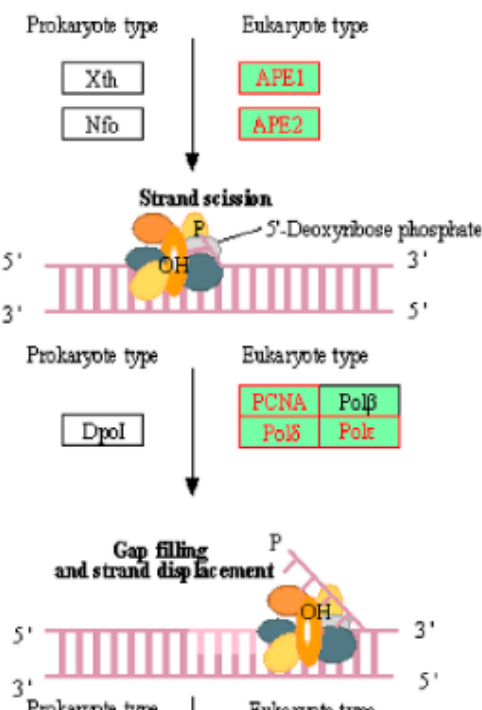

\begin{tabular}{l|l}
3 & Prokaryote type \\
\hline
\end{tabular}
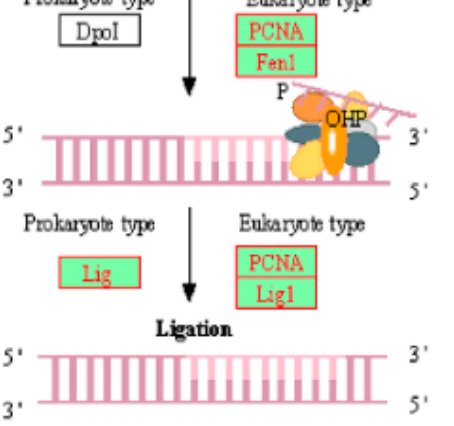

BER complex

Short patch BER

APEX Lig III

XRCC1

PolB PARP

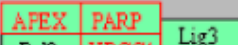

\begin{tabular}{|l|l|l}
\hline PolP & XRCC1 Lig \\
\hline
\end{tabular}

Long patch BER

APEX FENI

PCHA PAPP

Polp 1 PAPP

Lig1

\begin{tabular}{|l|l|l|}
\hline PolB & APEX & Fenl \\
\hline
\end{tabular}

Lig1 PCNA PARP

Pols Pole

Figure 3. Visualization of the GSEA-enriched genes from the leading-edge subset of the base excision repair pathway in CPT-CEF-treated colon cancer cells. The pathway was extracted from the KEGG database, and the GSEA-enriched genes obtained from the data set were highlighted in red. The underexpression of these genes is predicted to have an impact in the downstream signaling involved during base excision repair. 

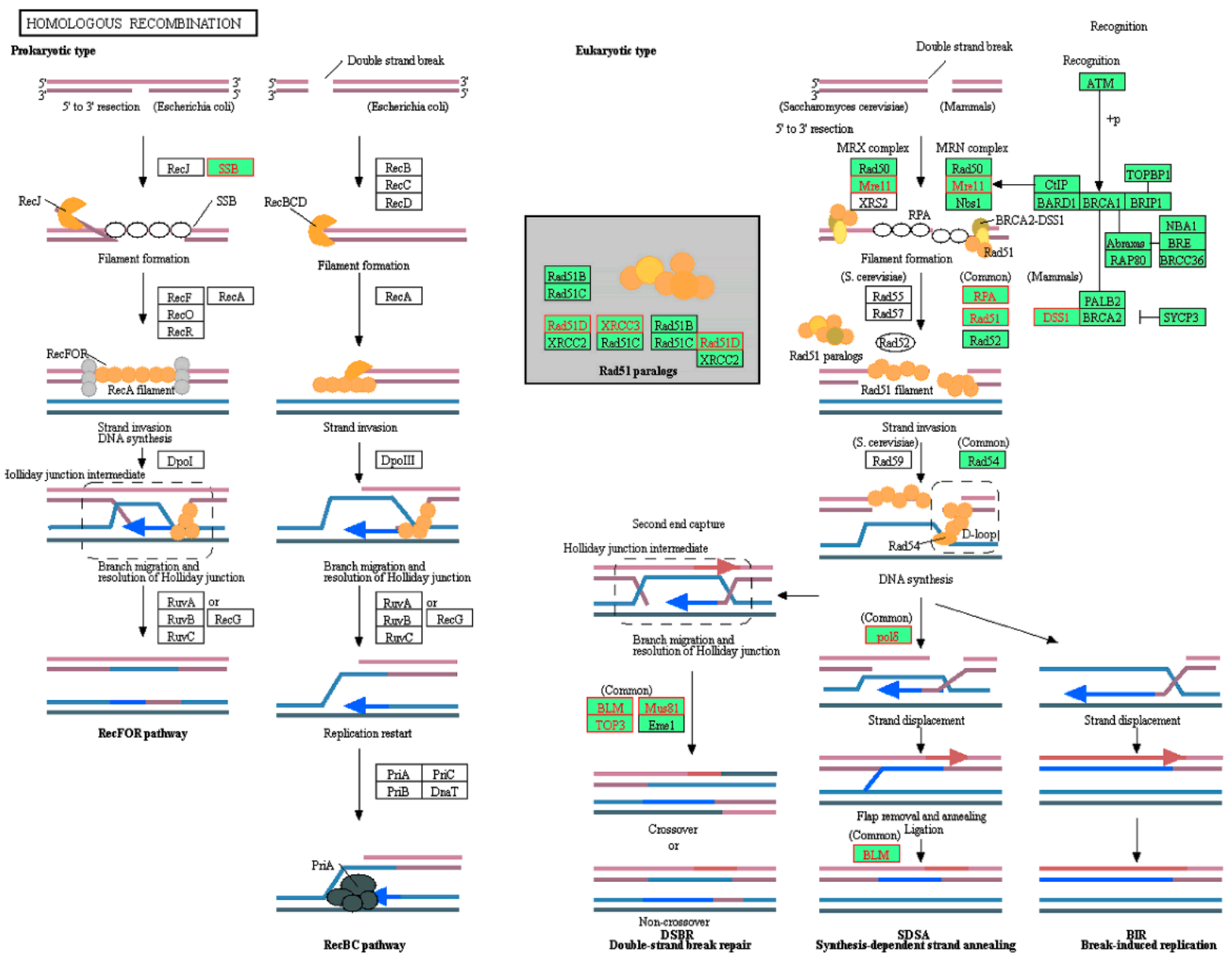

Figure 4. Visualization of the GSEA-enriched genes from the leading-edge subset of the homologous recombination pathway in CPT-CEF-treated colon cancer cells. The pathway was extracted from the KEGG database, and the GSEA-enriched genes obtained from the data set were highlighted red. The underexpression of these genes is predicted to have an impact in the downstream signaling involved during homologous recombination.

High mobility group box 1 (HMGB1) is a highly conserved expressed nuclear protein vital to reverse DNA damage and maintain genomic stability by preserving nucleosome structure and regulating DNA replication and transcription in cells [31]. Reduced activity of HMGB1 leads to higher frequency of DNA damage when exposed to radiation, carcinogens, or chemotherapeutic or oxidative stress-inducing agents [32]. It can translocate from the nucleus to the cytoplasm following post-translational modifications, including acetylation, phosphorylation, and methylation [33]. The secretion of HMGB1 from cells can trigger a cascade of inflammatory reactions. It can bind to Receptor for Advanced Glycation End products (RAGE) or Toll-like receptors (TLRs), which eventually activates the nuclear transcription factor $\mathrm{\kappa B}(\mathrm{NF}-\mathrm{kB})$ signal transduction pathway, and upregulates various apoptotic factors to cause cell death $[31,33]$. Meanwhile, APEX1-encoded DNA(apurinic or apyrimidinic site) lyase has been shown to be highly expressed in a variety of tumors, including liver [34], colorectal [35], gastric [36], and non-small-cell lung cancer [37]. Gene expression profiling demonstrated that increased APE1 correlated with glioblastoma recurrence in patients [38]. The result of Gene Set Enrichment Analysis (GSEA) on hepatocellular carcinoma showed that the expression of APEX1 was related to a DNA damage repair pathway and its high expression could result in poor prognosis [39]. POLE3 is one of the four components in the DNA polymerase epsilon holoenzyme [40]. POLE3 can interact with other histone-fold proteins to bind to DNA in a sequence-independent manner and initiate the synthesis of the leading strand during replication of DNA [41]. Mutations in 
Pole are associated with colon and endometrial cancer, and hence downregulation of POLE3 could interrupt DNA repair [42].

\section{MISMATCH REPAIR}

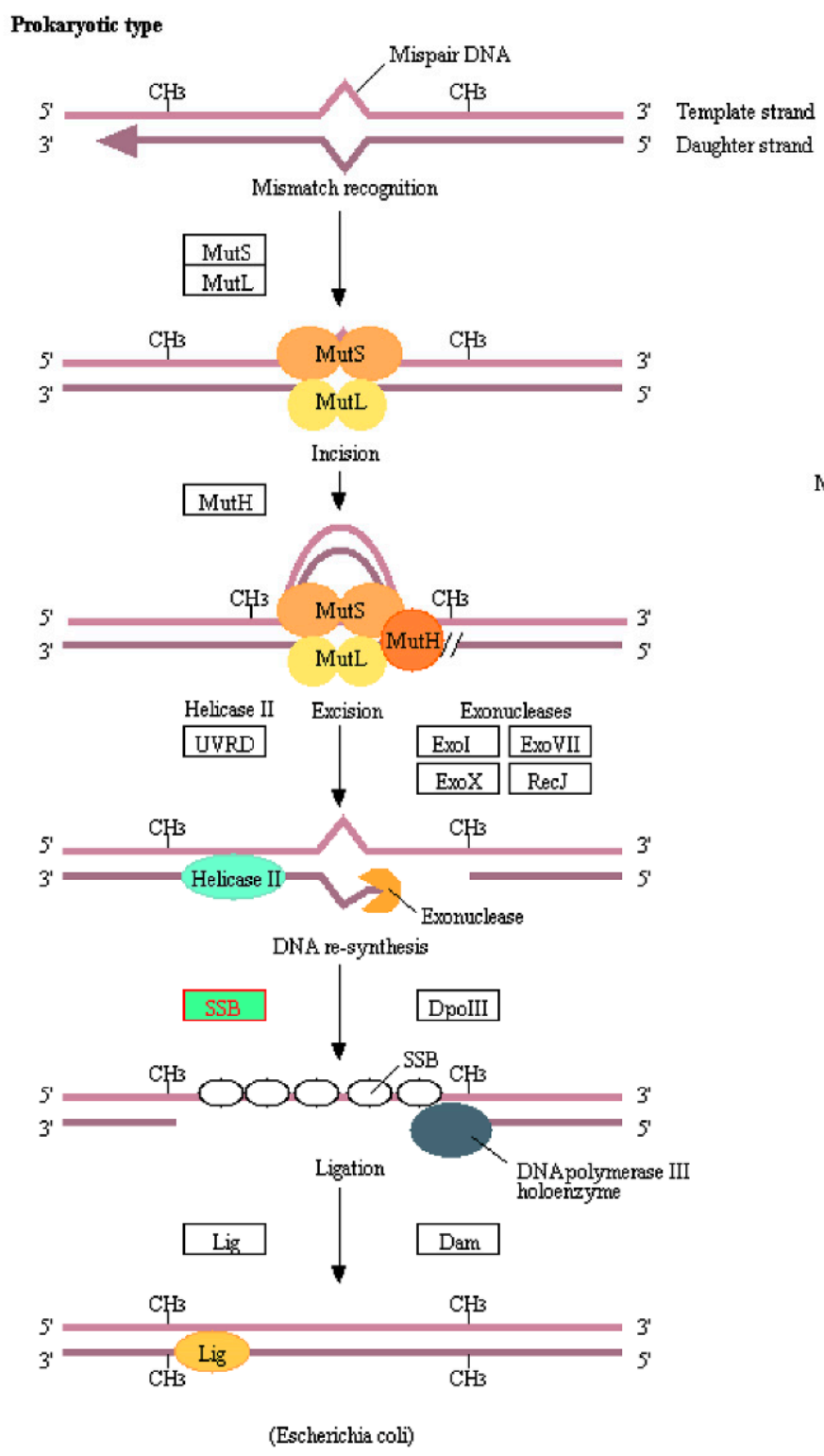

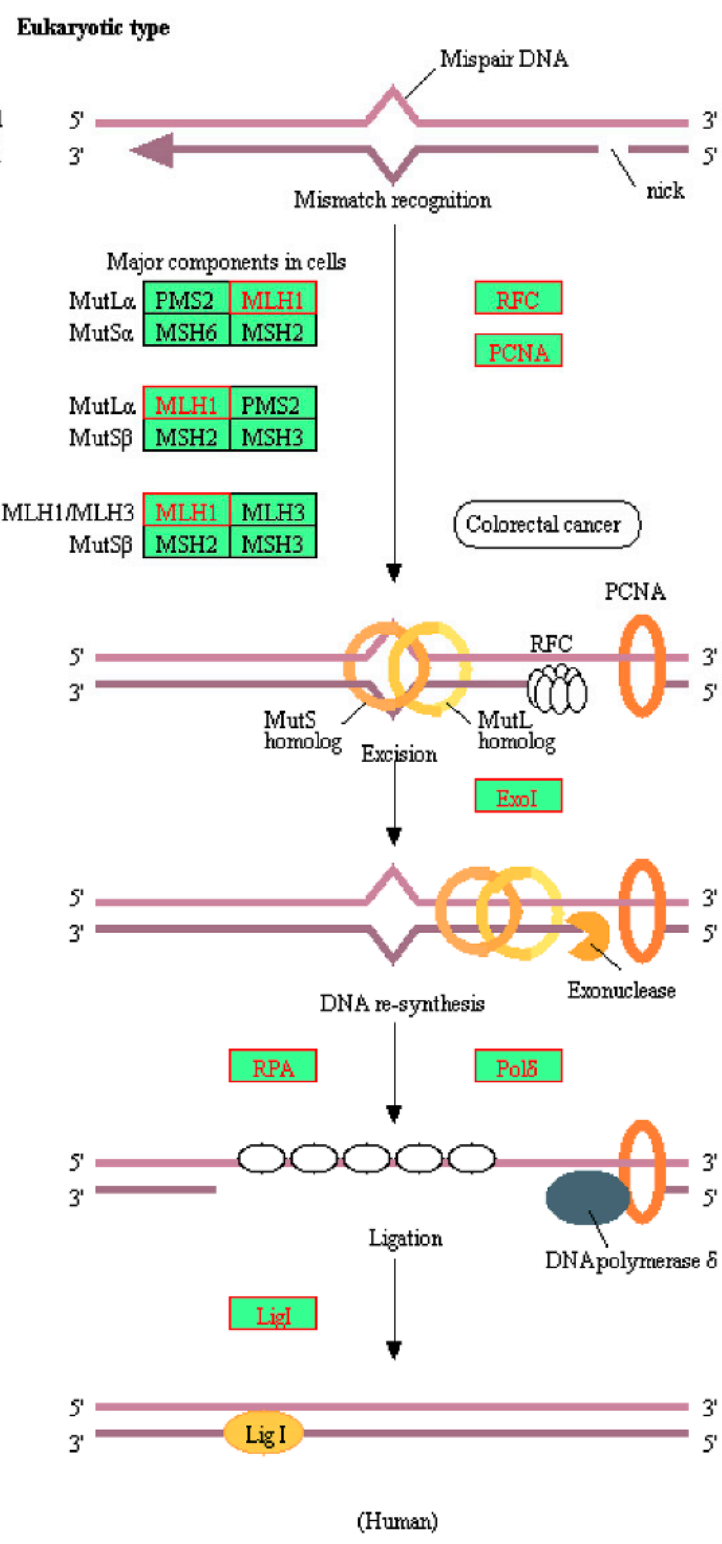

Figure 5. Visualization of the GSEA-enriched genes from the leading-edge subset of the mismatch repair pathway in CPT-CEF-treated colon cancer cells. The pathway was extracted from the KEGG database, and the GSEA-enriched genes obtained from the data set were highlighted red. The underexpression of these genes is predicted to have an impact in the downstream signaling involved during mismatch repair.

In addition, this study also found that PKM gene expression was modified upon treatment with CPT-CEF in the HT29 cell line. Pyruvate Kinase Muscle (PKM) is a group of isozymes made up of PKM1 and PKM2. PKM has direct control of the transcription activity of genes related to various cells' metabolism. Therefore, aberrancy in PKM expression could lead to tumorigenesis [43-45]. Prior studies have shown that PKM2 has a close relationship with cellular proliferation, migration, anchorage-independent growth, and in tumor growth and liver metastasis in vivo [46-49]. PKM2 was demonstrated to promote dsDNA breaks repair through homologous recombination, and has been suggested as a 
cause of cancer resistance to genotoxic therapies [50]. We can corroborate that the repression of PKM2 may affect the histone machinery through epigenetic alterations.

In a bigger context, aberrant epigenetic modification of these genes could lead to deregulated signal transduction as well as a promotion of tumorigenic processes. For example, the suppression of HMGB1 can lead to a loss of maintenance in genomic stability, and as such, the regulation of DNA replication and transcription would be affected, which leads to uncontrolled cell proliferation. On the other hand, POLE3 functions in DNA extension, and its aberrant downregulation could affect DNA repair, thereby leading to more mutations and further tumor progression. As such, further investigations into these candidates could yield newer formulations that can effectively target these epigenetic mechanisms to impede tumor growth.

\section{Materials and Methods}

\subsection{Treatment of HT29 Colon Cancer Cells with CPT-CEF Nanocompound}

A stock of the CPT-CEF nanocompound solution was prepared by dissolving it in $10 \%$ dimethyl sulfoxide (DMSO) (Nacalai, Kyoto, Kyoto, Japan) in complete culture medium before the experiment. The HT29 human colorectal carcinoma cell line used in this study was obtained from the Laboratory of Vaccine and Immunotherapy (LIVES) Institute of Biosciences (IBS, Seri Kembangan, Selangor, Malaysia), UPM. Firstly, the cells were seeded at a concentration of $1 \times 10^{4}$ cells $/ \mathrm{mL}$ of culture medium in a 6-well culture plate. It consisted of the Roswell Park Memorial Institute (RPMI) 1640 Medium (Nacalai, Kyoto, Kyoto, Japan), 10\% Fetal Bovine Serum (Nacalai, Kyoto, Kyoto, Japan) and 1\% Penicillin/Streptomycin. The culture was then incubated at $37{ }^{\circ} \mathrm{C}$ in a $5 \% \mathrm{CO}_{2}$ incubator for $24 \mathrm{~h}$. After that, the supernatant was discarded. The nanocompound solution was then added to the culture medium to obtain a final concentration of $133.5 \mu \mathrm{g} / \mathrm{mL}$ (IC50) $(n=3)$. The DMSO content in the stock solution did not exceed $1 \%$ of final nanocompound concentration in the culture medium. The cell culture was then incubated for $48 \mathrm{~h}$ in a $5 \% \mathrm{CO}_{2}$ incubator before conducting the RNA-seq experiment.

\subsection{Isolation of Total RNA from HT29 Colon Cancer Cells and Library Preparation for Sequencing}

The HT29 colon cancer cell line was incubated with CPT-CEF, as mentioned in our previous study [15]. Then, the total RNA was extracted from the cells using the RNeasy mini kit according to the recommendation from the manufacturer (Qiagen, Hilden, Germany). Samples with an RNA integrity (RIN) value of more than 7 and high purity (A260/A280 ratio $=2$ ) were used for the downstream experiment. The Bioanalyzer 2100 system (Agilent Technologies, Santa Clara, CA, USA) was used to measure RNA integrity, whereas the NanoDrop 2000 Spectrophotometer (Thermo Scientific, Waltham, MA, USA) was used to measure the A260/A280 ratio.

\subsection{Library Preparation for RNA Sequencing}

Library preparation was performed using the NEBNext ${ }^{\circledR}$ Ultra $^{\mathrm{TM}}$ II RNA Library Prep Kit for Illumina ${ }^{\circledR}$ (New England Biolabs, Ipswich, MA, USA) according to the manufacturer's protocol. The isolated RNA was further enriched to obtain mRNA. Total RNA was incubated with $50 \mu \mathrm{L}$ of oligo dT beads and binding buffer at $65^{\circ} \mathrm{C}$ for $5 \mathrm{~min}$ in a PCR tube. The tubes were then placed onto a magnetic stand to capture the beads. The contents of the tubes were washed several times to remove residual rRNA and other RNA types. Then, the beads were mixed with $50 \mu \mathrm{L}$ of Tris buffer and incubated in a thermal cycler at $80{ }^{\circ} \mathrm{C}$ for $2 \mathrm{~min}$, followed by a cooling step to a temperature of $25^{\circ} \mathrm{C}$ before elution.

The mRNA was used to synthesize the first-strand cDNA. A reaction mix was set up and incubated for $10 \mathrm{~min}$ at $25{ }^{\circ} \mathrm{C}, 15 \mathrm{~min}$ at $42{ }^{\circ} \mathrm{C}$, and $15 \mathrm{~min}$ at $70{ }^{\circ} \mathrm{C}$, before finally putting it on hold at $4{ }^{\circ} \mathrm{C}$. Immediately after that, the samples were incubated with the reaction mix for $1 \mathrm{~h}$ at $16{ }^{\circ} \mathrm{C}$ to produce the second cDNA strand. Purification of the double-stranded cDNA was then carried out using NEBNext Sample Purification Beads, and magnetic capture of the DNA strands was carried out. cDNA was eluted in Tris-EDTA 
buffer and used to ligate to unique adaptors to create cDNA libraries by incubating at $20{ }^{\circ} \mathrm{C}$ for $15 \mathrm{~min}$. The ligation reaction was then purified using the NEBNext Sample Purification Beads. Finally, PCR enrichment of adapter-ligated cDNA was performed to expand the library before sequencing. The quality of the library was then assessed using the Bioanalyzer 2100 system. All the samples showing a single peak with the size of approximately $300 \mathrm{bp}$ on the electropherogram were used for RNA-seq.

\subsection{RNA-Seq Data Processing and Differential Gene Expression Analysis}

The Illumina HiSeq2000 system (Illumina, Hayward, CA, USA) was used for the RNA-seq study. Paired-end sequencing was performed $(2 \times 100 \mathrm{bp})$. Once completed, the quality of the sequences was assessed using the FastQC tool. Alignment, annotation, and quantification were then performed using the Salmon tool (available at github.com, accessed 13 January 2021) and the GRCh38 homosapiens assembly (asia.ensembl.org, accessed 13 January 2021) as a reference transcriptome. Differential expression analysis of CPT-CEF-treated and untreated colon cancer cells were then performed using the DeSeq2 tool (Bioconductor.org, accessed 14 January 2021). After performing the analysis, the differentially expressed genes were extracted.

\subsection{Functional Enrichment Analysis and Identification of Genes in Epigenetics}

The g:Profiler tool was used to perform over-representation analysis (ORA) (https: //biit.cs.ut.ee/gprofiler/, accessed 16 January 2021). By using a threshold of $p<0.10$ and 2-fold change, the DEGs were loaded into the tool. Gene Ontology (GO) was the database used for the study. The output files were summarized and clustered using REViGO (http:/ / revigo.irb.hr/, accessed 16 January 2021). Functional enrichment was carried out using the GSEA tool (https://www.gsea-msigdb.org/gsea/index.jsp, accessed 16 January 2021). KEGG (c2.cp.kegg.v7.2.symbols.gmt, accessed 16 January 2021) was the database used for this analysis. The data were annotated using the database from MSigdb (Human_ENSEMBL_Gene_ID_MSigDB.v7.2.chip, accessed 16 January 2021). The default settings were used for the analysis, except for the following parameters: permutation number-1000; permutation type - gene set; gene ranking metric - log2 ratio of classes. Data mining was then performed by cross-referencing the enriched gene sets with the EpiFactors database (https: / / epifactors.autosome.ru/, accessed 16 January 2021). The associated genes in epigenetics were extracted and tabulated.

\section{Conclusions}

The defect of DNA repair mechanisms in human colon cancer might be due to the downregulated genes that have a significant role in controlling the transcription of genes involved in base excision repair. Overall, this study postulates that treatment with CPT-CEF could inhibit the proliferation of HT29 cells, most probably by reversing this dysregulation. Current transcriptomic results deserve our attention as many pieces of literature have pointed out that efficient DNA repair in cancer cells could confer resistance to radio- and chemotherapy. More mechanistic studies have to be performed to confirm the results and to re-evaluate the role of these genes before formulating a strategy to prevent or halt the cancer cell growth.

Author Contributions: A.F., A.E.-H.K. and J.B.T. were responsible for composing the manuscript; A.F., P.L.M. and S.K.S. were responsible for conceiving the experimental study design, analyzing the data, and editing the manuscript; A.F., A.E.-H.K. and J.B.T. performed the experiments, analyzed the data, produced the figures, and performed the statistical analysis. A.A., P.L.M. and S.K.S. analyzed and edited the manuscript. All authors were involved in reviewing the manuscript. All authors have read and agreed to the published version of the manuscript.

Funding: The authors extend their appreciation to the Deputyship for Research and Innovation, Ministry of Education in Saudi Arabia for funding this research work through the project number 375213500 . 
Institutional Review Board Statement: Not applicable.

Informed Consent Statement: Not applicable.

Data Availability Statement: The datasets presented in this study can be found in the Gene Expression Ominibus (GEO) public repository with accession number GSE165875.

Acknowledgments: The authors acknowledge Rajan Mariappan from Madurai Kamaraj University for the kind gift of CPT-CEF as research material in this study.

Conflicts of Interest: The authors have no conflict of interest to declare.

Sample Availability: Samples of the compounds are not available from the authors.

\section{References}

1. Nebbioso, A.; Tambaro, F.P.; Dell'Aversana, C.; Altucci, L. Cancer epigenetics: Moving forward. PLoS Genet. 2018, 14, 1-25. [CrossRef]

2. Hillyar, C.; Rallis, K.S.; Varghese, J. Advances in Epigenetic Cancer Therapeutics. Cureus 2020, 12, e11725. [CrossRef]

3. Sharma, S.; Kelly, T.K.; Jones, P.A. Epigenetics in cancer. J. Carcinog. 2009, 31, 27-36. [CrossRef]

4. Rius, M.; Lyko, F. Epigenetic cancer therapy: Rationales, targets and drugs. Oncogene 2012, 31, 4257-4265. [CrossRef] [PubMed]

5. Vlachakis, D.; Chrousos, G. Epigenetics. Int. J. Epigenet. 2020, 1, 1. [CrossRef]

6. Jung, G.; Hernández-Illán, E.; Moreira, L.; Balaguer, F.; Goel, A. Epigenetics of colorectal cancer: Biomarker and therapeutic potential. Nat. Rev. Gastroenterol. Hepatol. 2020, 17, 111-130. [CrossRef] [PubMed]

7. Lee, K.H.; Song, C.G. Epigenetic regulation in bladder cancer: Development of new prognostic targets and therapeutic implications. Transl. Cancer Res. 2017, 6, S677-S688. [CrossRef]

8. Goldman, S.L.; Hassan, C.; Khunte, M.; Soldatenko, A.; Jong, Y.; Afshinnekoo, E.; Mason, C.E. Epigenetic modifications in acute myeloid leukemia: Prognosis, treatment, and heterogeneity. Front. Genet. 2019, 10, 133. [CrossRef] [PubMed]

9. Carlberg, C.; Molnár, F. Human Epigenetics: How Science Works. Human Epigenetics: How Science Works; Springer: Berlin/Heidelberg, Germany, 2019. [CrossRef]

10. Klutstein, M.; Nejman, D.; Greenfield, R.; Cedar, H. DNA methylation in cancer and aging. Cancer Res. 2016, 76, 3446-3450. [CrossRef] [PubMed]

11. Audia, J.E.; Campbell, R.M. Histone modifications and cancer. Cold Spring Harb. Perspect. Biol. 2016, 8, a019521. [CrossRef]

12. Neja, S.A. Site-Specific DNA Demethylation as a Potential Target for Cancer Epigenetic Therapy. Epigenet. Insights 2020, 13, 2516865720964808. [CrossRef]

13. Sharma, V.; Lansdell, T.A.; Peddibhotla, S.; Tepe, J.J. Sensitization of tumor cells toward chemotherapy: Enhancing the efficacy of camptothecin with imidazolines. Chem. Biol. 2004, 11, 1689-1699. [CrossRef]

14. Rajan, M.; Krishnan, P.; Pradeepkumar, P.; Jeyanthinath, M.; Jeyaraj, M.; Ling, M.P.; Arulselvan, P.; Higuchi, A.; Munusamy, M.A.; Arumugam, R.; et al. Magneto-chemotherapy for cervical cancer treatment with camptothecin loaded Fe3O4 functionalized $\beta$-cyclodextrin nanovehicle. RSC Adv. 2017, 7, 46271-46285. [CrossRef]

15. Krishnan, P.; Rajan, M.; Kumari, S.; Sakinah, S.; Priya, S.P.; Amira, F.; Danjuma, L.; Ling, M.P.; Fakurazi, S.; Arulselvan, P.; et al. Efficiency of newly formulated camptothecin with $\beta$-cyclodextrin-EDTA-Fe3O4 nanoparticle-conjugated nanocarriers as an anti-colon cancer (HT29) drug. Sci. Rep. 2017, 7, 1-16. [CrossRef]

16. Zhang, G.; Zeng, X.; Li, P. Nanomaterials in cancer-therapy drug delivery system. J. Biomed. Nanotechnol. 2013, 9, 741-750. [CrossRef] [PubMed]

17. Tsakiris, N.; Papavasileiou, M.; Bozzato, E.; Lopes, A.; Vigneron, A.M.; Préat, V. Combinational drug-loaded lipid nanocapsules for the treatment of cancer. Int. J. Pharm. 2019, 569, 118588. [CrossRef] [PubMed]

18. Simões, S.M.N.; Rey-Rico, A.; Concheiro, A.; Alvarez-Lorenzo, C. Supramolecular cyclodextrin-based drug nanocarriers. Chem. Commun. 2015, 51, 6275-6289. [CrossRef]

19. Nie, L.; Ou, Z.; Yang, S.; Xing, D. Thermoacoustic molecular tomography with magnetic nanoparticle contrast agents for targeted tumor detection. Med. Phys. 2010, 37, 4193-4200. [CrossRef]

20. Strasser, A.; Vaux, D.L. Cell Death in the Origin and Treatment of Cancer. Mol. Cell 2020, 78, 1045-1054. [CrossRef]

21. Sousa, F.G.; Matuo, R.; Tang, S.W.; Rajapakse, V.N.; Luna, A.; Sander, C.; Pommier, Y. Alterations of DNA repair genes in the NCI-60 cell lines and their predictive value for anticancer drug activity. DNA Repair 2015, 28, 107-115. [CrossRef] [PubMed]

22. Verbinnen, I.; Boens, S.; Ferreira, M.; Szekér, K.; Van Wijk, L.; Van Eynde, A.; Bollen, M. Enhanced DNA-repair capacity and resistance to chemically induced carcinogenesis upon deletion of the phosphatase regulator NIPP1. Oncogenesis 2020, 9, 1-8. [CrossRef]

23. de Almeida, L.C.; Calil, F.A.; Machado-Neto, J.A.; Costa-Lotufo, L.V. DNA damaging agents and DNA repair: From carcinogenesis to cancer therapy. Cancer Genet. 2021, 252-253, 6-24. [CrossRef]

24. Galatage, S.T.; Hebalkar, A.S.; Gote, R.V.; Mali, O.R.; Killedar, S.G.; Bhagwat, D.A.; Kumbhar, V.M. Design and characterization of camptothecin gel for treatment of epidermoid carcinoma. Future J. Pharm. Sci. 2020, 6, 1-11. [CrossRef] 
25. Venditto, V.J.; Simanek, E.E. Cancer Therapies Utilizing the Camptothecins: A Review of in Vivo Literature. Biophys. Chem. 2010, 7, 307-349. [CrossRef]

26. Martino, E.; Della Volpe, S.; Terribile, E.; Benetti, E.; Sakaj, M.; Centamore, A.; Sala, A.; Collina, S. The long story of camptothecin: From traditional medicine to drugs. Bioorg. Med. Chem. Lett. 2017, 27, 701-707. [CrossRef] [PubMed]

27. Du, G.H. Natural small Molecule Drugs from Plants; Springer: Berlin/Heidelberg, Germany, 2018; pp. 1-741. [CrossRef]

28. Li, G.; Zhao, M.; Zhao, L. Lysine-mediated hydroxyethyl starch-10-hydroxy camptothecin micelles for the treatment of liver cancer. Drug Deliv. 2020, 27, 519-529. [CrossRef]

29. Kaliyamoorthi, K.; Ramasamy, S.; Pillai, A.S.; Alexander, A.; Arivarasu, A.; Enoch, I.V.M.V. Camptothecin-loaded holmium ferrite nanocarrier. Expanded activity on breast cancer cells. Mater. Lett. 2021, 285, 129164. [CrossRef]

30. Li, L.Y.; Guan, Y.D.; Chen, X.S.; Yang, J.M.; Cheng, Y. DNA Repair Pathways in Cancer Therapy and Resistance. Front. Pharmacol. 2021, 11, 2520. [CrossRef]

31. Xue, J.; Suarez, J.S.; Minaai, M.; Li, S.; Gaudino, G.; Pass, H.I.; Carbone, M.; Yang, H. HMGB1 as a therapeutic target in disease. J. Cell. Physiol. 2021, 236, 3406-3419. [CrossRef]

32. Tripathi, A.; Shrinet, K.; Kumar, A. HMGB1 protein as a novel target for cancer. Toxicol. Rep. 2019, 6, 253-261. [CrossRef]

33. Wang, S.; Zhang, Y. HMGB1 in inflammation and cancer. J. Hematol. Oncol. 2020, 13, 13-16. [CrossRef]

34. Zheng, R.; Zhu, H.L.; Hu, B.R.; Ruan, X.J.; Cai, H.J. Identification of APEX2 as an oncogene in liver cancer. World J. Clin. Cases 2020, 8, 2917-2929. [CrossRef] [PubMed]

35. Hong Beum, K.; Lim, H.J.; Lee, H.J.; Park, J.U.N.; Park, S.G. Evaluation and Clinical Significance of Jagged-1-activated Notch Signaling by APEX1 in Colorectal Cancer. Anticancer Res. 2019, 39, 6097-6105. [CrossRef]

36. Hong Beum, K.; Lee, H.J.; Kim, G.B.; Lim, H.J.; Park, J.U.N.; Park, S.G. Clinical Significance of Jagged-1 Activated by APEX1 as a Chemoresistance Factor in Advanced Gastric Cancer. Anticancer Res. 2020, 40, 1897-1904. [CrossRef]

37. Peng, L.; Liu, Y.; Chen, J.; Du, X.; Zhang, R.; Cheng, M.; Wu, Y.; Chen, M.; Zhong, Y.; Shen, D.; et al. APEX1 Regulates Alternative Splicing of Key Tumorigenesis Genes in Non-Small-Cell Lung Cancer. 2020. Available online: https://assets.researchsquare.com/ files/rs-108181/v1/fe97aa87-e593-4f20-be86-8bd2c3208a70.pdf?c=1610799165 (accessed on 20 July 2021).

38. Hudson, A.L.; Parker, N.R.; Khong, P.; Parkinson, J.F.; Dwight, T.; Ikin, R.J.; Zhu, Y.; Chen, J.; Wheeler, H.R.; Howell, V.M. Glioblastoma recurrence correlates with increased APE1 and polarization toward an immuno-suppressive microenvironment. Front. Oncol. 2018, 8, 314. [CrossRef] [PubMed]

39. Cao, L.; Cheng, H.; Jiang, Q.; Li, H.; Wu, Z. APEX1 is a novel diagnostic and prognostic biomarker for hepatocellular carcinoma. Aging 2020, 12, 4573-4591. [CrossRef] [PubMed]

40. Siamishi, I.; Iwanami, N.; Clapes, T.; Trompouki, E.; O'Meara, C.P.; Boehm, T. Lymphocyte-Specific Function of the DNA Polymerase Epsilon Subunit Pole3 Revealed by Neomorphic Alleles. Cell Rep. 2020, 31, 107756. [CrossRef] [PubMed]

41. Hatakeyama, K.; Ohshima, K.; Nagashima, T.; Ohnami, S.; Ohnami, S.; Serizawa, M.; Shimoda, Y.; Maruyama, K.; Akiyama, Y.; Urakami, K.; et al. Molecular profiling and sequential somatic mutation shift in hypermutator tumours harbouring POLE mutations. Sci. Rep. 2018, 8, 1-13. [CrossRef] [PubMed]

42. Eng, C. POLE mutations in colorectal cancer: A new biomarker? Lancet Gastroenterol. Hepatol. 2016, 1, 176-177. [CrossRef]

43. Anastasiou, D.; Yu, Y.; Israelsen, W.J.; Jiang, J.K.; Boxer, M.B.; Hong, B.S.; Tempel, W.; Dimov, S.; Shen, M.; Jha, A.; et al. Pyruvate kinase M2 activators promote tetramer formation and suppress tumorigenesis. Nat. Chem. Biol. 2012, 8, 839-847. [CrossRef]

44. Han, D.; Wei, W.; Chen, X.; Zhang, Y.; Wang, Y.; Zhang, J.; Wang, X.; Yu, T.; Hu, Q.; Liu, N.; et al. NF-kB/RelA-PKM2 mediates inhibition of glycolysis by fenofibrate in glioblastoma cells. Oncotarget 2015, 6, 26119-26128. [CrossRef]

45. Zahra, K.; Dey, T.; Mishra, S.P.; Pandey, U. Pyruvate Kinase M2 and Cancer: The Role of PKM2 in Promoting Tumorigenesis. Front. Oncol. 2020, 10, 159. [CrossRef] [PubMed]

46. Shiroki, T.; Yokoyama, M.; Tanuma, N.; Maejima, R.; Tamai, K.; Yamaguchi, K.; Oikawa, T.; Noguchi, T.; Miura, K.; Fujiya, T.; et al. Enhanced expression of the M2 isoform of pyruvate kinase is involved in gastric cancer development by regulating cancer-specific metabolism. Cancer Sci. 2017, 108, 931-940. [CrossRef] [PubMed]

47. Kuranaga, Y.; Sugito, N.; Shinohara, H.; Tsujino, T.; Taniguchi, K.; Komura, K.; Ito, Y.; Soga, T.; Akao, Y. SRSF3, a splicer of the PKM gene, regulates cell growth and maintenance of cancer-specific energy metabolism in colon cancer cells. Int. J. Mol. Sci. 2018, 19, 3012. [CrossRef]

48. Méndez-Lucas, A.; Li, X.; Hu, J.; Che, L.; Song, X.; Jia, J.; Wang, J.; Xie, C.; Driscoll, P.C.; Tschaharganeh, D.F.; et al. Glucose catabolism in liver tumors induced by c-MYC can be sustained by various PKM1/PKM2 ratios and pyruvate kinase activities. Cancer Res. 2018, 77, 4355-4364. [CrossRef] [PubMed]

49. Okazaki, M.; Fushida, S.; Tsukada, T.; Kinoshita, J.; Oyama, K.; Miyashita, T.; Ninomiya, I.; Harada, S.; Ohta, T. The effect of HIF-1 $\alpha$ and PKM1 expression on acquisition of chemoresistance. Cancer Manag. Res. 2018, 10, 1865-1874. [CrossRef]

50. Sizemore, S.T.; Zhang, M.; Cho, J.H.; Sizemore, G.M.; Hurwitz, B.; Kaur, B.; Lehman, N.L.; Ostrowski, M.C.; Robe, P.A.; Miao, W. Pyruvate kinase M2 regulates homologous recombination-mediated DNA double-strand break repair. Cell Res. 2018, 28, 1090-1102. [CrossRef] 